\title{
Mapeando as Inter-relações para a Efetivação do Consumo Sustentável sob a Perspectiva Governo-Empresa-Sociedade ${ }^{1}$
}

\section{Mapping the interrelationships for the practice of sustainable consumption from the perspective of Government-Business-Society}

\author{
Minelle Enéas da Silva \\ Doutorando em Administração pela Universidade Federal do Rio Grande do Sul - UFRGS \\ Mestre em Administração pela Universidade Federal de Pernambuco - UFPE \\ Professor da Universidade Federal do Rio Grande do Sul \\ Endereço: Rua General Lima e Silva, 30 - Centro - Porto Alegre-RS. \\ CEP: CEP: 90.050-100,e-mail: minele.adm@gmail.com
}

Ana Paula Gabriel Oliveira

. Universidade Federal de Pernambuco. Graduada em Administração pela UFPE Av. Prof. Moraes Rego, 1235 - Cidade Universitária, Recife - PE CEP: 50.670-901, e-mail: apaulagabriel@gmail.com

\section{RESUMO}

As discussões envolvendo o desenvolvimento sustentável como paradigma emergente vêm sendo realizadas identificando-se a necessidade de mudança no pensamento individualista e consumista da sociedade. Nessa perspectiva, visualizando a necessidade de reestruturação nas formas de produção e consumo atuais, assume-se como abordagem teórica o consumo sustentável, considerando-o como um padrão de consumo resultante de inter-relações entre atores sociais nesse sentido. Em se considerando esses diferentes atores, a presente pesquisa tem como objetivo identificar como se inter-relacionam Governo, Empresa e Sociedade para a efetivação do consumo sustentável, considerando as especificidades do setor econômico estudado. Na medida em que se busca na prática a aplicação da teoria, identificou-se na Companhia Elétrica de Pernambuco - CELPE uma contribuição ao consumo sustentável como resultado dos projetos desenvolvidos pela empresa, selecionando-a como estudo de caso. Realiza-se, portanto, uma pesquisa exploratório-descritiva com a abordagem qualitativa. Com os resultados, identificaram-se os diferentes papéis desenvolvidos tanto pelos atores sociais selecionados como de outros atores envolvidos para a efetivação desse padrão sustentável de consumo. A partir da visualização prática das questões discutidas, percebe-se desse modo a originalidade e relevância que o trabalho acrescenta nas discussões sobre a temática do consumo sustentável.

Palavras-chave: Desenvolvimento Sustentável. Consumo Sustentável. Atores Sociais.

\begin{abstract}
Discussions involving sustainable development as emerging paradigm have been conducted identifying the need for change in thinking individualist and consumerist society. From this perspective, seeing the need for restructuring in the form of current production and consumption, is assumed as theoretical approach sustainable consumption, considering it as a pattern of consumption resulting from inter-relations between social actors in this sense. In considering these different actors, this research aims to identify how they interrelate Government, Business and Society for the realization of sustainable consumption, considering the specifics of the economic sectors studied. In the search for practical application of theory, identified on the Companhia Elétrica de Pernambuco - CELPE a contribution to sustainable consumption as a result of projects developed by the company, selecting it as a case study. Is held, therefore, an exploratory-descriptive research with a qualitative approach. With the results, identified the different roles developed by both the social actors selected as other stakeholders for the realization of sustainable pattern of consumption. From the practical view of the issues discussed, it is perceived that way the originality and relevance to the job adds in the discussions on the theme of sustainable consumption.
\end{abstract}

Keywords: Sustainable Development. Sustainable Consumption. Social Actors.

\footnotetext{
${ }^{1}$ Artigo recebido em 02.07.2012. Revisado por pares em 20.07.2012 (blind review). Reformulado em 25.07.2012. Recomendado para publicação em 25.07.2012 por José Ribamar Marques de Carvalho (Editor Científico). Publicado em 07.08.2012.
} 


\section{INTRODUÇÃO}

Nos últimos anos, tem-se tornado perceptível que o crescimento econômico, a evolução tecnológica, a busca por uma melhoria na qualidade de vida, bem como as modificações realizadas nas necessidades humanas vem gerando uma grande pressão sobre o meio ambiente. Este fato demonstra que existem peculiaridades a serem consideradas, haja vista que os recursos naturais possuem suas limitações e direcionam a necessidade de um novo pensar coletivo. Tais aspectos indicam cada vez mais a necessidade de redirecionamento da prática capitalista atual para uma que consiga abranger aspectos mais coletivos e de interesses mais amplos em relação a um desenvolvimento contínuo da atividade humana, ou seja, o desenvolvimento sustentável.

Para que uma sociedade se envolva com essa forma alternativa de desenvolvimento, faz-se necessário que as pessoas se preocupem em satisfazer suas necessidades sem que isto possa vir a comprometer as gerações futuras (SACHS, 2007; WCDE, 1987). Ou seja, devem se utilizar os recursos do planeta de forma que seu impacto prejudique o menos possível o equilíbrio entre o meio ambiente e a sociedade. Combater o desperdício de materiais e garantir a economia de recursos importantes, como água e energia é uma maneira inteligente e comedida no uso dos recursos naturais. Considerando sempre a necessidade de harmonia entre as dimensões social, econômica e ambiental (ELKINGTON, 2001).

A relação entre sustentabilidade e consumo é estreita. Todavia percebe-se, no contexto ao qual está inserida a sociedade, que os atuais padrões de consumo não são compatíveis com as ideias de desenvolvimento sustentável. Verifica-se assim a necessidade de que haja uma consciência por parte de diferentes atores sociais em relação tanto ao modelo de desenvolvimento emergente considerado como em relação à busca por um padrão sustentável de consumo, que nasce da mudança de atitude dos consumidores e da sociedade em geral. De forma genérica, pode-se dizer que esse novo padrão de consumo "utiliza os recursos naturais para satisfazer as necessidades atuais, sem comprometer as necessidades e aspirações das gerações futuras." (GOMES, 2006, p.26).

Alinhando a complexidade inerente a temática com as discussões desenvolvidas na área acadêmica, percebe-se que de forma mais operacional pode considerar o consumo sustentável como um padrão de consumo direcionado para esse modelo de desenvolvimento alternativo, no qual se faz necessário equiparar as responsabilidades de cada um dos atores sociais envolvidos, em um setor econômico, por meio de um processo de conscientização e incorporação de seus diferentes papéis nesse sentido (SILVA, 2010; SILVA; CORRÊA, 2010). Desse modo, cada ator social considerado, nomeadamente Empresa-GovernoSociedade, deve entender que faz parte desse contexto transformador e buscar atuar de forma ativa nesse processo.

Em se observando a dinâmica de mercado a qual a sociedade está inserida, percebe-se que muitas empresas estão modificando suas práticas organizacionais e direcionando-as para questões socioambientais. Dentre as muitas organizações que estão inseridas nesse contexto, encontra-se a Companhia Elétrica de Pernambuco - CELPE, que por meio de projetos de eficiência energética vem trabalhando para uma reestruturação na prática do consumo no setor. A iniciativa de desenvolvimento de projetos está envolvida com a ideologia da empresa, mas especificamente no campo energético, uma regulamentação estimulou a ampliação desses 
projetos criados. Dentre os muitos projetos destaca-se o Projeto Nova Geladeira, direcionado para a disseminação de um caráter mais consciente no consumo de energia elétrica.

Assim sendo, utilizando-se a empresa apresentada como estudo de caso para apresente pesquisa, entendendo que houve uma interação entre os atores sociais para que a responsabilidade organizacional pudesse ser posta em prática, toma-se como objetivo identificar como se inter-relacionam Governo, Empresa e Sociedade para a efetivação do consumo sustentável, considerando as especificidades do setor econômico estudado, no caso o elétrico. Utiliza-se pesquisa exploratória e descritiva, com abordagem qualitativa, para o atendimento da proposta de pesquisa. Como instrumentos de coleta de dados utilizam-se levantamento documental, aplicação de questionários e realização de entrevistas, analisados por meio de análise estatística e documental.

Como melhor forma de compreender o objetivo proposto o presente artigo está dividido em cinco partes distintas. Além dessa parte introdutória são apresentados num segundo momento os aspectos teóricos norteadores da pesquisa assim identificam-se uma discussão sobre desenvolvimento sustentável e consumo sustentável, com o intuito de apresentar as argumentações utilizadas para o entendimento do fenômeno. A seguir são indicados os procedimentos metodológicos. No quarto momento, observa-se a apresentação e análise dos resultados, com uma visualização do setor elétrico, a identificação do consumo sustentável no setor, identificando os papéis do governo, da organização selecionada e do indivíduo nesse sentido e, por fim, as considerações finais.

\section{DISCUSSÃO TEÓRICA}

\subsection{Desenvolvimento Sustentável}

Levando em consideração as constantes mudanças que estão ocorrendo em todo o mundo, sejam elas econômicas, sociais ou ambientais, fica perceptível que tais transformações são o reflexo das ações humanas sobre o meio ambiente, as quais podem ser percebidas por meio das mudanças climáticas, das economias abaladas, bem como pelo impacto social resultante desse processo. Em meio a esse contexto complexo, percebe-se que as atitudes individuais em relação à coletividade, em sua maioria, direcionam seus holofotes para os aspectos intrínsecos a cada um, focalizando as prioridades e disponibilidades por esses percebidas.

Cada vez mais se percebe a necessidade de mudança no modelo de desenvolvimento ao qual se está submetido, por entender que o pensamento capitalista traz a ideia de abundância de recursos, bem como incentiva as práticas individualistas causando dentre outras consequências a intensificação do consumismo, ou seja, aquele consumo extravagante de bens e serviços (GIACOMINI FILHO, 2008). Para que uma mudança de paradigma possa ser posta em prática, o desafio mais importante, segundo Ray (1999, p.21), "consiste em aplicar o conhecimento interior, a intuição, a compaixão e o espírito a prosperidade, num período de mudança constante e descontínua", ou seja, deve-se seguir um pensamento distinto do praticado de forma que haja uma continuidade dessas ações.

O desenvolvimento sustentável surge, nesse sentido, como alternativa a essa necessidade de mudança, em se considerando que um conjunto de ações deve ser praticado para a efetivação do mesmo. Seu conceito mais completo foi definido no Relatório de 
Brundtland, no qual é entendido como "um processo de mudança em que a exploração dos recursos, a direção dos investimentos, a orientação do desenvolvimento tecnológico e a mudança institucional estão todos em harmonia" para que as necessidades humanas possam ser satisfeitas atualmente e no futuro (WCDE, 1987). Necessitando a busca pela harmonização entre suas dimensões fundamentais, a saber: econômica, social e ambiental (SACHS, 2007).

De fato, o direcionamento das atividades para uma nova forma de prática organizacional necessita de uma "mudança no pensamento mecanicista para o sistêmico, e de um sistema de valores baseado na dominação para um sistema baseado na parceria" (CASAGRANDE JR., 2003, p.3), indicando que o novo modelo alternativo a ser praticado serve como subsídio para as ações organizacionais. Para Schumacher (2001) o problema deve ser entendido em sua totalidade, buscando reconhecer e desenvolver um novo estilo de vida, com novos métodos de produção e novos padrões de consumo. Já na visão de Buarque (2008) essa transição de um modelo insustentável para outro que contemple princípios capazes de modificar positivamente o contexto deve abarcar mudanças estruturais e iniciativas transformadoras da base da organização da sociedade e da economia.

Ao longo das últimas décadas, intensificaram-se as discussões sobre como modificar essa tendência negativa a qual o mundo está se direcionando. Desta forma, pode-se buscar o reconhecimento sobre a melhor maneira de se alcançar a harmonia entre esses critérios fundamentais do desenvolvimento sustentável, entendendo que os diferentes atores sociais possuem papéis específicos para a efetivação desse modelo de desenvolvimento emergente, assim sendo como apresentado na Figura 01 deve-se considerar tais aspectos para que se perceba e se consiga direcionar as atividades sociais práticas para uma nova visão desenvolvimentista.

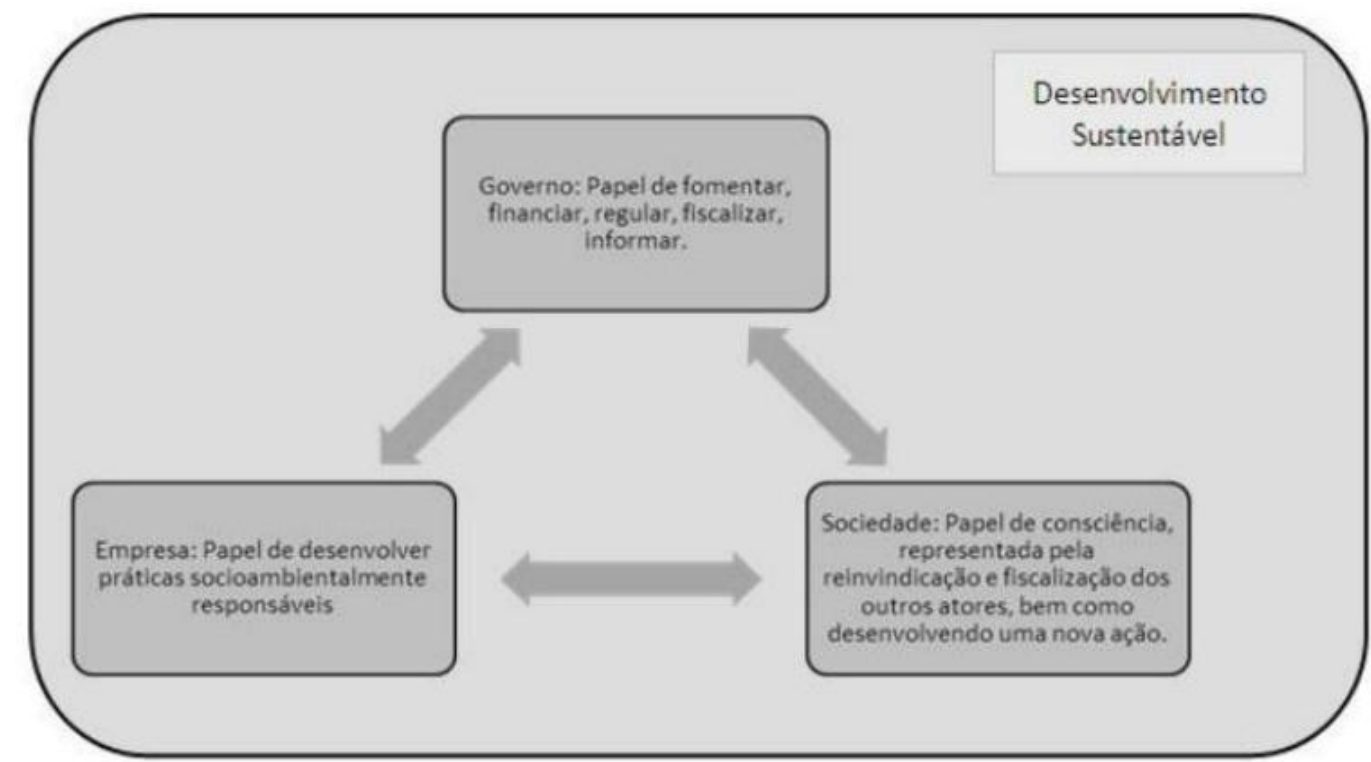

Figura 01: Relações sociais para o desenvolvimento sustentável Fonte: Corrêa et al. (2010)

Apesar de se apresentar como uma questão ampla na qual, normalmente, direciona-se toda a responsabilidade de seu alcance ao Estado, é notável a necessidade de que toda a 
sociedade se envolva em harmonizar as dimensões básicas do desenvolvimento sustentável no sentido de que se consiga usufruir os recursos necessários da melhor maneira possível para a continuidade tanto das gerações atuais como das futuras, no atendimento de suas necessidades. Tal fato é citado por Buarque (2008) como a solidariedade intra e inter geracional, respectivamente. Considerando-se os aspectos apresentados na esquematização anteriormente apresentada.

\subsection{Consumo Sustentável}

A prática do consumo acompanha o ser humano em todos os momentos de sua existência, direta ou indiretamente, o que ratifica a ideia de que é indissociável o viver sem consumir (SILVA, 2010). De acordo com o Instituto Akatu (2001), consumir é um processo que, geralmente, é realizado de forma automática e, muitas vezes, de forma impulsiva, devendo-se entender que o mesmo está relacionado com a decisão sobre o que consumir, por que consumir, como consumir e de quem consumir, além da efetivação da compra e o pósconsumo, no momento que é necessário descartar o que foi utilizado. Esse processo pode ser observado de forma singular na compra de bens materiais e de serviços prestados.

Considerada como uma atividade inerente a um processo cultural de uma sociedade, o consumo tem pretensões e alcance global (McCRAKEN, 2003; SLATER, 2002), portanto, é uma atividade realizada nas diferentes nações em se considerando as particularidades de cada localidade. Desse modo, a cultura de consumo vai além da reprodução da vida cotidiana, atingindo de modo dominante um alcance prático e uma profundidade ideológica que permite estruturar e subordinar as outras culturas (SLATER, 2002). A sociedade de consumo, a qual a população está submetida na atualidade, demonstra o quão cultural a prática de consumir envolve as relações interpessoais.

Diante do consumismo observado na maioria das populações ao redor do mundo, como parte da cultura de muitos países (ASSADOURIAN, 2010), verifica-se cada vez mais necessária a mudança no modelo desenvolvimentista, alinhada a uma mudança no paradigma consumista de modo que seja possível a continuidade nas práticas de consumo em escala mundial. Isso pode ser conquistado com a modificação do paradigma de consumo voltado a um pensamento mais holístico das ações desempenhadas (PNUMA, 2001), buscando redirecionar a visão do consumo moderno, na medida em que esse é caracterizado como a produção exclusiva para a venda, no mercado, aos consumidores (SLATER, 2002).

Com o evolutivo desenvolvimento do mercado direcionado a essa visão mais sistêmica quanto às características de consumo, percebe-se que o mesmo, com o passar do tempo, não é afetado somente por aqueles que são consumidores no sentido econômico, mas também por aqueles que em suas ações, mesmo que indiretamente, moldam a procura e compra de bens e serviços (PORTILHO, 2005). Evidenciando-se, assim, uma nova perspectiva de compra que além de valorizar as questões econômicas, buscam englobar uma maior quantidade de variáveis inerentes à oferta do produto, dentre as quais se pode identificar a preocupação empresarial com os aspectos sociais e ambientais.

A mudança nas práticas de consumo da sociedade reflete o momento cultural a qual a mesma está inserida, perante as dinâmicas e demandas requeridas, necessitando-se um direcionamento coletivo para a efetivação da forma de desenvolvimento emergente, o sustentável. Cada vez mais, seguindo a ideia de mudança de paradigma e considerando-a 
viável, Santos et al. (2008) afirmam que estão surgindo novas preocupações por parte do consumidor, as quais mudam o foco individualista de seu consumo para uma visão mais ampla em termos de consciência do mesmo. Surge, portanto, o movimento na sociedade por um consumo mais responsável.

Nesse novo contexto, com a intenção de uma nova prática de consumo, diante da necessidade no desenvolvimento de novos papéis sociais direcionados a esse objetivo, que de forma ampla assume a denominação de consumo sustentável. Para que esse seja compreendido há que se identificar a existência de uma complementaridade entre tipos diferentes de consumo mais responsáveis. Percebe-se que a partir de uma ideia hierárquica entre esses tipos de consumo, tornam-se geradores de complexidade numa sequencia linear as ideias de consumo verde, de consumo consciente e, por fim, de consumo sustentável, alcançando desse modo o objetivo do novo paradigma de consumo.

$\mathrm{Na}$ literatura sobre a temática, percebe-se que há uma confusão entre os conceitos na visão de muitos autores nacionais, os quais buscam normalmente trabalhar com a ideia ou de consumo verde de produtos ou de práticas de consumo consciente sem a efetiva distinção entre esses (BEDANTE; SLONGO, 2004; COSTA; OLIVEIRA, 2009; GOMES, 2006; GONÇALVES-DIAS; MOURA, 2007; ORTIGOZA, 2002). Todavia, Silva (2010) busca realizar um delineamento claro dessa ideia hierárquica para compreensão da temática. Diante dessas considerações, percebe-se que o consumo sustentável analogamente ao conceito de desenvolvimento sustentável pode ser considerado como a prática de consumo que utiliza os recursos naturais para satisfazer as necessidades atuais, sem comprometer as necessidades e aspirações das gerações futuras (GOMES, 2006; CORTEZ; ORTIGOZA, 2007).

Para que o consumo sustentável possa ser praticado Jackson (2007) indica ser necessária uma adequação dos padrões de consumo a nova realidade social, entendendo que a partir da redução no consumo de boa parte dos materiais, bem como um redirecionamento das práticas até então desenvolvidas facilitam seu alcance. Assim sendo, Silva (2010) define o consumo sustentável como sendo o padrão de consumo resultante da inter-relação de atores sociais direcionado ao alcance do desenvolvimento sustentável. Segundo o autor é necessário levar em consideração que diferentes atores sociais influenciam a efetivação dessa prática de consumo, cada uma com papéis singulares as suas capacidades.

Nesse sentido, percebe-se que para que o consumo sustentável possa ser efetivado podem estar envolvidos nessa rede de interações: Governo, Empresa, Sociedade Civil (indivíduo), Mídia, Terceiro Setor, dentre outros atores (MICHAELIS, 2003). Para tanto o governo pode assumir o papel de regulamentador, de fiscalizador, de fomentador, de estimulador do desenvolvimento de tecnologias limpas, além de apoiador de pesquisas que visem disseminar informações sobre a produção e consumo nesse novo contexto (CORRÊA et al., 2010; PNUMA, 2001). De forma relacionada com esse ator as organizações com finalidade lucrativa devem assumir sua responsabilidade nesse sentido assumindo e direcionando suas atividades para questões socioambientais que consigam desenvolver o setor econômico ao qual se está inserido com relação ao desenvolvimento sustentável.

O papel das organizações nesse sentido está basicamente na atuação dessas novas práticas direcionada para uma produção sustentável, isso por meio de inovações organizacionais, ou seja, soluções inovadoras desenvolvidas para essa nova atuação na dinâmica mercadológica. Outro ator considerado como eixo para a efetivação de um consumo sustentável, o consumidor, assume o papel de consumidor cidadão, a partir de uma prática de 
consumo consciente, ao desempenhar papel de consciência no momento da compra, bem como um comportamento de consumidor preocupado com as questões pertinentes ao desenvolvimento sustentável (OLIVEIRA; CÂNDIDO, 2010). Esse é o desafio fundamental para o movimento dos consumidores (PNUMA, 2001) nesse novo contexto.

Com essas considerações, percebe-se que a interação mútua e complementaridade entre os atores sociais, envolvem-se naturalmente de forma sistematizada com três eixos fundamentais: o governo, a organização e a sociedade, os outros atores devendo ser considerados no estímulo a esse novo padrão de consumo. A partir desse delineamento teórico, vale salientar que as diferentes economias, bem como os diferentes setores econômicos possuem práticas distintas que facilitam a efetivação do consumo sustentável (TUKKER et al., 2008). Com isso, torna-se necessário o reconhecimento dos aspectos utilizados para a realização da presente pesquisa no que se refere ao setor elétrico estudado.

\section{PROCEDIMENTOS METODOLÓGICOS}

Com o objetivo de identificar como se inter-relacionam Governo-Empresa-Sociedade para efetivação de um consumo sustentável, a presente pesquisa assume uma abordagem qualitativa na medida em que o fenômeno estudado especifica e representa um processo de reflexão e análise de um contexto para uma compreensão detalhada do objeto de estudo (OLIVEIRA, 2005). A utilização da referida abordagem justifica-se ainda, segundo Richardson et al. (2008, p.79), "por ser uma forma adequada para entender a natureza de um fenômeno social". Para tanto, a mesma está caracterizada como pesquisa exploratória e descritiva, para melhor compreensão do estudo.

A pesquisa caracteriza-se como exploratória, por proporcionar, segundo Gil (1991, p.45), uma maior familiaridade para com o problema, com vistas a torná-lo mais explícito e compreensível, e descritiva por apresentar a descrição das características de dada população ou fenômeno em estudo, com caráter conclusivo para análise (GIL, 1991; MALHOTRA, 2006). Entendendo que a temática do consumo sustentável ainda apresenta poucos trabalhos alinhados com a perspectiva de desenvolvimento sustentável continuamente discutida por diferentes atores sociais, é nesse contexto que se insere a presente pesquisa na medida em que busca evidenciar os diferentes papéis de cada um desses atores sociais.

Para que se torne possível o levantamento de informações pertinentes ao estudo, salienta-se que o conceito utilizado como norteador da pesquisa quanto ao consumo sustentável é aquele que indica a efetivação de um padrão de consumo, resultante de interrelações entre atores sociais, direcionados para o desenvolvimento sustentável (SILVA, 2010). A partir dessa argumentação teórica, identificou-se no desenvolvimento prático de suas atividades que a Companhia Elétrica de Pernambuco (CELPE) em meio ao desenvolvimento de seus projetos, vem auxiliando para o consumo sustentável no setor de elétrico, na medida em que envolvido com um grupo de atores sociais facilita o consumo consciente de seus clientes e visa à redução do impacto ambiental de suas atividades.

Desse modo, percebendo o envolvimento desses atores sociais com objetivos coletivos almejados, assume-se como método na presente pesquisa o estudo de caso, já que com as atividades dessa organização selecionadas envolvem a pesquisa num campo de reconhecimento e apresentação de características peculiares sobre a temática. $\mathrm{O}$ estudo de caso se apresenta como método adequado quando o investigador deseja: a) definir tópicos de 
forma mais superficial do que específica e aprofundada; b) cobri condições contextuais e não apenas o fenômeno de estudo; e c) se basear em múltiplas fontes de evidências e não em algumas poucas (YIN, 1993). Facilitando desse modo, o alcance do objetivo proposto como norteador da pesquisa.

Como instrumentos de coletas de dados selecionaram-se o levantamento documental, a aplicação de questionários e a realização de entrevistas. A utilização de documentos como fontes de dados justifica-se pela facilidade de embasamento informacional para posterior análise, essa etapa estando relacionada com a procura pelas regulamentações realizadas no setor elétrico que podem auxiliar para o entendimento do papel governamental, uma verificação na web site da empresa selecionada com o intuito de identificar informações que possam subsidiar a análise - inclusive seus relatórios, além de notícias publicadas pela mídia que fazem menção aos projetos da empresa.

As entrevistas foram realizadas o representante de responsabilidade social e com o gestor de eficiência energética da empresa, com representantes do terceiro setor (articulador do Instituto Ethos e representante da Associação de Voluntários para o Serviço Internacional AVSI). Para uma melhor análise optou-se pelo anonimato dos entrevistados. Já os questionários foram aplicados com contemplados e propensos a participar do projeto, com o intuito de identificar a contribuição do projeto para a comunidade. A partir desses dados foram coletadas informações dos atores sociais selecionados para análise nessa pesquisa.

No que se refere à análise de dados, utilizou-se o Software SPSS 17.0 para análise estatística, bem como uma análise de conteúdo, buscando explicitar o conteúdo das entrevistas, esta análise baseando-se na perspectiva categorial, por meio da análise temática, visando uma compreensão mais rápida e eficaz nos discursos diretos e simples (BARDIN, 2009). Esse tipo de análise realizada em três etapas: em três etapas: a) pré-análise ou organização do material coletado nas entrevistas, bem como dos documentos levantados; b) análise do material propriamente dito, no qual os dados foram categorizados e embasados na literatura pertinente ao estudo; e c) tratamento dos resultados, sendo feita a interpretação destes dados e confrontando-os com os resultados, formulando-se as considerações finais.

\section{APRESENTAÇÃO E ANÁLISE DOS RESULTADOS}

\subsection{A Companhia Elétrica de Pernambuco - CELPE e o Contexto Elétrico Brasileiro}

Com características peculiares se comparado aos outros mercados de energia do mundo, o setor elétrico brasileiro tem sua base geradora com predominância de hidrelétricas que, apesar de ser uma fonte secundária e renovável de energia, produzem grandes impactos sobre o meio ambiente, sentidos ao longo e além do tempo de vida da usina hidrelétrica no seu entorno (SOUSA, 2000). No Brasil, a partir dos anos 1960 o segmento energético teve seu controle centralizado em poder do setor público, por meio de empresas públicas federais e estaduais, tanto no que se refere à geração, integração de sistemas e distribuição de energia (GOLDEMBERG; PRADO, 2003).

Como reflexo da crise fiscal que ocorreu no país no final dos anos 1980 e com os adiamentos das necessidades de expansão da oferta de energia tornou-se impossibilitado para as empresas estatais a manutenção nos investimentos necessários para o setor elétrico, o que propiciou a entrada da iniciativa privada e a privatização dos ativos existentes nesse mercado 
de forma pulverizada. Percebendo-se que para uma melhor atuação nesse processo de privatização, não houve inicialmente, a criação por parte do Estado de mecanismos necessários para a nova regulação do setor, o que gradativamente foi sendo trabalhado e organizado pelo governo como forma de melhorar as práticas no setor.

Nesse contexto de transição, ocorreu uma série de reformas no setor, com uma série de políticas regulatórias até que chegou ao novo modelo institucional do sistema energético nacional, inaugurado pela lei 9.427/96, que instituiu a ANEEL (Agência Nacional de Energia Elétrica) e a lei 9.648/98, que definiu as regras de entrada, tarifas e estrutura de mercado, entre outras coisas (PIRES, 2000). Com o surgimento de um ambiente concorrencial no setor elétrico, segundo Fernandino e Oliveira (2010), as empresas se viram inseridas numa perspectiva ambiental e organizacional, na qual se mostrava necessário definir estratégias para sua atuação, bem como o ajustamento de suas estruturas e delineamento de processos internos para uma melhor adaptação a esse novo contexto.

$\mathrm{Na}$ década de 2000, ao atravessar um período de escassez de chuvas, em se considerando a grande quantidade de hidrelétricas no país, surgiu a necessidade de novas formas de geração da matriz energética nacional. Nesse contexto, destacam-se nessa nova geração energética as termelétricas (biomassa) e o gás natural, tendo o governo que adotar medidas de apoio ao desenvolvimento de projetos de hidrelétricas, de fontes não convencionais e de conservação de energia (GRUPO NEOENERGIA, 2008). Concomitantemente a evolução e dinâmica reconhecida no setor elétrico brasileiro, ao longo dos anos surgiram as empresas responsáveis pela geração e distribuição de energia.

Dentre aquelas que foram criadas nesse período temporal de evolução do setor elétrico brasileiro encontra-se a Companhia Energética de Pernambuco - CELPE. Fundada em 10 de fevereiro de 1965 com o papel de distribuidora de energia do Estado de Pernambuco, a empresa passa a ter caráter privado no final da década de 1990, quando foi adquirida em leilão por um consórcio chamado de Guaraniana, formado pela Caixa de Previdência dos Funcionários do Banco do Brasil (PREVI), pela carteira de investimentos do Banco do Brasil (BB S/A) e pelo Grupo Iberdrola, reconhecida hoje como Grupo Neoenergia (CELPE, 2010a).

Atualmente a CELPE atende a mais de três milhões de clientes e leva energia a 184 municípios pernambucanos, ao distrito de Fenando de Noronha e ao município de Pedras de Fogo, no Estado da Paraíba (CELPE, 2010b). Na prestação de seus serviços a empresa adotou uma gestão socialmente responsável, implementando suas ações de responsabilidade social e sustentabilidade por meio de programas estruturados, assumindo destaque nacional entre as melhores distribuidoras de energia do Brasil (CELPE, 2010b). A atuação social da empresa estudada focaliza questões de cultura, educação e meio ambiente, sendo desenvolvidos projetos com o objetivo de atender a esse foco, tendo como exemplo de atuação os projetos: Luz no Empreendedorismo, Ação Integrada, Telecentro Comunitário, Agente Celpe, Logisverde, Encontro Celpe e Comunidades Especiais.

Um dos principais meios de desenvolver as ações de responsabilidade social da empresa é por meio de projetos de Eficiência Energética, que contemplam alguns desses focos e têm o objetivo de proporcionar à sociedade um uso mais eficaz e racional da energia elétrica, evitando os desperdícios e reduzindo também os custos incorridos com seu uso. Dentre esses projetos destaca-se o chamado Projeto Nova Geladeira que está envolvido numa rede de parcerias, com a qual estimula-se o consumo consciente de energia da população de 
baixa renda beneficiada pelo projeto, e com isso em meio as interações sociais que desenvolve para a execução do projeto, estimula a efetivação do consumo sustentável no setor elétrico.

Segundo dados da CELPE, até o momento da realização da pesquisa, como resultados das ações envolvidas com o projeto, já foram realizadas a troca de 33.595 geladeiras e 491.407 lâmpadas fluorescentes nas comunidades de baixa renda de Pernambuco. São metas para o ano de 2011, a visita a mais 90.000 residências em comunidades de baixa renda, a entrega de refrigerados a 50.000 beneficiados e de 180.000 lâmpadas fluorescentes, além da realização de palestras de esclarecimento quanto a eficiência energética. Para que todas essas ações possam ser desenvolvidas, necessita-se de muitas interações nesse sentido, consideradas nesse estudo como aquelas facilitadoras do alcance de um consumo sustentável.

\subsection{Consumo Sustentável no Setor Elétrico}

Compreendendo que o consumo sustentável relaciona-se com o estimulo a efetivação de um novo padrão de consumo, a partir das inter-relações dos atores sociais e direcionado para a forma de desenvolvimento emergente (SILVA, 2010), é possível afirma que está havendo o estímulo a partir das práticas apresentadas nesse trabalho, na medida em que todos os atores sociais atuantes no setor estão envolvidos com um objetivo comum que é a busca por uma nova prática de consumo, mais eficiente e responsável pelo consumidor final.

Percebe-se que existe uma rede de inter-relações entre esses atores sociais, que, de forma complementar, conseguem estimular e mudar a prática de consumo final da energia. Desse modo, faz-se necessário reconhecer de forma individual quais ações que estão sendo desenvolvidas por esses atores para que se torne possível a efetivação desse novo paradigma de consumo.

\subsubsection{O Papel do Governo}

Dentre os muitos projetos desenvolvidos pela empresa, aquele considerado como um dos principais do Grupo Neoenergia, o Projeto Nova Geladeira, consiste na troca de geladeiras velhas de alto consumo de energia por uma nova geladeira com selo PROCEL de economia de energia. Num primeiro momento, o projeto parece não apresentar muitas contribuições para o contexto social, mas em se observando as contribuições e as possibilidades resultantes do mesmo admite-se que a ideologia da empresa, de reestruturação na maneira de consumo da população beneficiada é plausível.

Tais aspectos puderam ser observados, a partir do momento em que o governo atuou como agente regulador e estimulador, ao assumir a responsabilidade pela estruturação de um setor econômico, no caso o energético, devendo a empresa estar envolvida com a necessidade de mudança nas suas atividades cotidianas. Percebe-se que para que o consumo sustentável seja efetivado no setor elétrico, a atuação do governo assumiu aspecto de fundamental importância.

A partir do momento em que ele redefiniu sua forma de atuação que classicamente consistia em regulamentar a operação do monopólio no setor; definir e encaminhar políticas de interesse geral; e funcionar como proprietária enquanto empresas públicas (GOLDEMBERG; PRADO, 2003) para a criação de um mercado livre, ainda segundo os autores, por meio de incentivos à eficiência, identificou-se a intervenção de forma positiva do 
governo nesse contexto de produção consumo energético, como se pode observar com a Lei n $9.991 / 00$ :

\begin{abstract}
As concessionárias e permissionárias de serviços públicos de distribuição de energia elétrica ficam obrigadas a aplicar [...] no mínimo, vinte e cinco centésimos por cento em programas de eficiência energética no uso final. [...] As receitas de que trata este artigo deverão ser aplicadas nas seguintes atividades do setor elétrico: I - em programas de universalização do serviço público de energia elétrica; II - no financiamento de projetos socioambientais; III - em projetos de eficiência e pesquisa energética; e IV - no pagamento de faturas de energia elétrica de unidades consumidoras de órgãos estaduais e municipais (BRASIL, 2000).
\end{abstract}

Como se observa, o governo desenvolveu seu papel de forma direta na busca por melhor estruturação do setor. Para Fernandino e Oliveira (2010) o objetivo principal do governo quando criou essa lei era assegurar o desenvolvimento tecnológico e de gestão do setor elétrico. Esse fato para o WWF-Brasil (2007) está relacionado com a criação de cenários para setor, dentre os quais se pode observar o cenário Elétrico Sustentável, no qual o governo precisa aprovar e programar um plano estratégico para um setor mais eficiente e inovador, com medidas de eficiência energética e maior utilização de fontes renováveis de energia, como biomassa, eólica, solar e pequenas hidrelétricas. Esses aspectos podendo ser realizados nos diferentes governamentais sejam eles nacionais, estaduais ou regionais/municipais (TAYLOR, 2006). Necessitando assim reconhecer o papel das organizações nesse sentido.

\title{
4.2.2 O Papel da Empresa
}

A partir do momento em que o governo atuou como agente regulador, assumindo a responsabilidade pela estruturação de um setor econômico, no caso o energético, a empresa viu-se envolvida com a necessidade de mudança nas suas atividades cotidianas. A empresa assume o desenvolvimento de sua responsabilidade socioambiental, desempenhando seu papel de forma positiva para o consumo sustentável, estimulada pela regulamentação e assumindo que nesse caso seu papel seria a de desenvolver projetos condizentes com os critérios estabelecidos na lei, mas que representassem as suas ideologias, ou seja, que alinhassem o que foi imposto com o objetivo da organização. Ao incorporar essa responsabilidade, as atividades desenvolvidas pela organização, envolvidas com a Educação, Cultura e Meio Ambiente, puderam ser abordadas nos vários projetos nesse sentido.

Entendendo que a organização vem desempenhando sua responsabilidade nesse sentido, fica visível que a mesma está envolvida com questões socioambientais, isso sendo desenvolvido a pelo menos uma década pela empresa (CELPE, 2010b). Esse papel é reconhecido, já que segundo o articulador do Instituo Ethos com a organização, essa vem "mobilizando a rede empresarial pela sustentabilidade em Pernambuco". Essa prática influenciando todas as atividades da empresa, segundo a representante de RSE, já que "no momento da concepção de projetos existe um alinhamento na Neoenergia e com o comitê de sustentabilidade da holding". Esse projeto estando em consonância com a prática da responsabilidade social da empresa, "na medida em que noções básicas de educação e consumo consciente são repassadas para uma população carente de informações sobre as formas de preservação do ecossistema", complementa o representante de RSE.

Quando iniciou o processo de efetivação do Projeto Nova Geladeira, estudado até então, a empresa buscou parceria com o Banco do Brasil, ou seja, outro ator social uma 
Instituição Financiadora, capaz de auxiliar com as ideias da organização. Isso tudo com o foco no consumidor, nesse caso o ator social mais beneficiado com as parcerias e interações até então desenvolvidas. O consumidor, além de estar envolvido com o processo de conscientização e de ganho com a nova geladeira, deve assumir a sua responsabilidade de economizar energia para que toda a sociedade venha a ganhar, desse modo a empresa também estimula essa conscientização por parte do indivíduo beneficiado.

Nesse caminho de contribuição para um consumo sustentável no setor elétrico, observa-se claramente a atuação de pelo menos mais dois atores sociais, que são o funcionário da empresa, chamado de Agente Celpe, responsável pelo contato com o beneficiário e em muitos casos pelo ponto inicial na conscientização desse indivíduo, ou seja, apesar de representar a empresa, o colaborador enquanto indivíduo tem sua responsabilidade nesse contexto maior trabalhado. Outro ator é a ONG chamada de AVSI. Com a prestação de serviços a CELPE, operacionalizando o projeto, essa organização está envolvida com a comunidade e pode estar envolvida ainda com o processo de conscientização e com esse novo perfil de consumo.

Na mídia do estado, por meio de noticiários impressos ou virtuais, constantemente são identificados notícias que enaltecem o caráter responsável que a empresa desenvolve com esse projeto, mostrando benefícios e parcerias que são desenvolvidas em torno do objetivo principal do projeto. Dentre as reportagens identificam-se parcerias entre a CELPE e prefeituras da Região Metropolitana do Recife e do interior do estado, além de parcerias com outras organizações do terceiro setor como o Instituto Walmart com o intuito de beneficiar comunidades atendidas por seus projetos (CELPE, 2010c; DIÁRIO DE PERNAMBUCO, 2010; FOLHA PE; 2010). Desse modo percebe-se que estão havendo interações entre os diferentes atores sociais no sentido de dar continuidade a prática de consumo, mas de forma reestruturada e direcionada para um desenvolvimento sustentável.

Com essas considerações percebe-se que efetivamente a organização vem desempenhando seu papel de responsabilidade na medida em que ao desenvolver os projetos de eficiência energética, facilita a busca por uma prática de consumo responsável nos consumidores. Vale destacar a interação ativa dessa com muitos atores sociais, o que sugere o efetivo direcionamento para um consumo sustentável no setor. No desenvolvimento de suas atividades, as principais metas a serem atingidas até dezembro de 2011, segundo a empresa, é a realização de 90.000 visitas a residências, troca de 50.000 geladeiras e de 180.000 lâmpadas fluorescentes, além da continuidade do processo de conscientização sobre eficiência energética por parte da empresa. Salientando que a troca das lâmpadas é uma atividade inclusa no projeto macro da troca de geladeiras. Nesse contexto, torna-se importante ainda reconhecer o papel do indivíduo para que seja efetiva a interação proposta.

\subsubsection{O Papel do Indivíduo}

Como outro eixo de atores sociais direcionados para a efetivação do consumo sustentável, o consumidor-cidadão, além de estar envolvido com o processo de conscientização e de ganho com a nova geladeira, deve assumir a sua responsabilidade de economizar energia para que toda a sociedade venha a ganhar, desse modo a empresa também estimula essa conscientização por parte do indivíduo beneficiado. $O$ indivíduo deve ser atuante ativamente nesse processo, já que para que o consumo sustentável possa ser efetivado 
esse se apresenta como ator de extrema importância. Na busca pelo conhecimento da população pesquisada, percebe-se que a mesma possui um perfil mais feminino no qual $71,5 \%$ é do referido sexo enquanto que apenas $28,5 \%$ é do sexo masculino, a faixa etária dessa população está em sua maioria acima de 30 de anos e o gasto de $24,4 \%$ fica numa faixa de 21,00 a 30,00 reais, essa não ultrapassando o valor de 60,00 reais para a maioria dos respondentes.

Considerando que a população pesquisada já assume uma personalidade no desenvolvimento de suas atividades, bem como nos seus comportamentos enquanto consumidores assume-se que os mesmos possuem a capacidade de discernimento e incorporação das informações disseminadas por parte da organização que desenvolveu o projeto, além daquelas repassadas pelas organizações do terceiro setor (Instituto Ethos e Associação de Voluntários para o Serviço Internacional - AVSI) como aspecto paralelo ao processo de conscientização das organizações. Analisando os dados de pesquisa percebe-se a incorporação por parte desses indivíduos de consciência de seu papel (Tabela 01).

Tabela 1 - Práticas de comportamento da população pesquisada

\begin{tabular}{ll}
\hline \hline Prática do Consumidor & \multicolumn{1}{c}{ Respostas mais destacadas } \\
\hline $\begin{array}{l}\text { Utilização de lâmpadas fluorescentes em sua } \\
\text { residência }\end{array}$ & $59,3 \%$ apenas fluorescente \\
\hline $\begin{array}{l}\text { Deixa os eletrodomésticos na tomada enquanto não } \\
\text { estão sendo utilizados }\end{array}$ & $63,3 \%$ desliga da tomada esses eletrodomésticos \\
\hline Realiza alguma regra de economia em casa & $66,3 \%$ indica possuir uma \\
\hline $\begin{array}{l}\text { Acredita haver maiores benefícios que não apenas o } \\
\text { econômico }\end{array}$ & $66,3 \%$ indica que sim \\
\hline \hline
\end{tabular}

Fonte: Dados de pesquisa (2010).

Como se pode observar na tabela anterior, a população está redirecionando seus comportamentos enquanto consumidores, em sua maioria em reflexo ao processo de conscientização desenvolvido pela organização, para uma prática mais consciente, demonstrando um novo perfil de consumidor nesse contexto de estímulo a uma nova prática de consumo. Esses possuindo ainda o papel de pressionador na organização, no momento em que se percebe que as práticas organizacionais falham no desenvolvimento de suas atividades quanto ao consumo sustentável (OLIVEIRA; CÂNDIDO, 2010). Para um melhor reconhecimento da efetiva atuação do processo de conscientização nesses consumidores, questionou-se sobre a efetiva realização do mesmo e como isso influencia nas suas práticas. Num teste de correlação como se pode observar a seguir, percebe-se que estão havendo mudanças por parte da população beneficiada. 
Tabela 2 - Correlação de Pearson entre a conscientização e algumas práticas dos respondentes Processo de Conscientização

\begin{tabular}{|c|c|c|c|c|}
\hline Variável & $\begin{array}{c}\text { Valores } \\
\text { percentuais }\end{array}$ & $\begin{array}{r}\text { Coeficiente } \\
\text { de correlação }\end{array}$ & $\begin{array}{c}\text { Sig. } \\
\text { (2-tailed) }\end{array}$ & $\begin{array}{c}\mathrm{N} \\
\text { (amostra) }\end{array}$ \\
\hline \multirow{2}{*}{$\begin{array}{l}\text { Você já recebeu alguma orientação } \\
\text { sobre o uso de eletrodomésticos e a } \\
\text { importância de economizar energia? }\end{array}$} & $63,3 \% \mathrm{Sim}$ & \multirow[b]{2}{*}{1,000} & & \multirow[b]{2}{*}{270} \\
\hline & $36,7 \%$ Não & & . & \\
\hline \multirow{3}{*}{$\begin{array}{l}\text { Caso tenha tido orientação, houve } \\
\text { mudança nos seus hábitos? }\end{array}$} & $57,7 \% \mathrm{Sim}$ & \multirow{3}{*}{$1,000 * *$} & \multirow{3}{*}{0,000} & \multirow{3}{*}{260} \\
\hline & $4,2 \%$ Não & & & \\
\hline & $38,1 \% \mathrm{NR}$ & & & \\
\hline \multirow{3}{*}{$\begin{array}{l}\text { Na compra de eletrodomésticos você } \\
\text { procura saber se ele tem selo Procel? }\end{array}$} & $77 \% \mathrm{Sim}$ & \multirow{3}{*}{$0,206^{* *}$} & \multirow{3}{*}{0,001} & \multirow{3}{*}{270} \\
\hline & $19,6 \%$ Não & & & \\
\hline & $3,3 \% \mathrm{NR}$ & & & \\
\hline \multirow{3}{*}{$\begin{array}{l}\text { Você deixa a luz e eletrodomésticos } \\
\text { desligados enquanto não os utiliza? }\end{array}$} & $63,3 \%$ & \multirow{3}{*}{0,084} & \multirow{3}{*}{0,169} & \multirow{3}{*}{270} \\
\hline & $23,3 \%$ Não & & & \\
\hline & $13,3 \% \mathrm{NR}$ & & & \\
\hline
\end{tabular}

** Correlação é significativa ao nível 0,01.

Fonte: Dados de Pesquisa (2010)

A realização do teste de correlação é utilizada para buscar compreender o quão influenciador é o processo de conscientização, nesse caso, sobre os comportamentos selecionados. Como se percebe existe correlação direta entre os estímulos de consciência desenvolvidos pela CELPE, sobre os comportamentos dos indivíduos uma vez que a maioria das respostas indica a organização como principal fonte de conscientização, sobre a mudança de hábitos dos indivíduos e a compra de produtos com selo Procel, o que indica que quanto maiores as práticas nesse sentido então maior demonstra-se essa relação, ou seja, maior a conscientização do indivíduo. Identifica-se ainda que pelo contrário não existe relação no que se refere ao desligar a luz e os eletrodomésticos enquanto não utilizados, havendo a necessidade de melhor disseminação das informações. Para realizar o teste, entende-se ser necessária uma significância [sig. (2-tailed)] menor do que 0,01 , para uma intensa relação.

De forma mais parcial, a mídia entra como ator social com o poder de demonstrar como as ações da CELPE estão sendo desenvolvidas, e como se observou nas reportagens analisadas, na maioria das vezes reconhece-se a contribuição positiva que o projeto tem no desenvolvimento de suas atividades. De fato, ao se considerar a sistematização complexa a qual a execução desse projeto assume, na medida em que envolve uma grande gama de atores sociais, a saber: Governo, Empresa, Instituição Financiadora, Comunidade (Indivíduos), Funcionário, Mídia, Organização do Terceiro Setor, recebendo resultados positivos o Meio Ambiente e possivelmente outros atores que não foram identificados a partir dos dados levantados nessa pesquisa, pode-se dizer que é possível a efetivação de um consumo sustentável, na área de consumo de energia, seguindo essa ideia até então apresentada.

\section{CONSIDERAÇÕES FINAIS}

$\mathrm{Na}$ busca pela efetivação de um consumo sustentável, direcionado para o desenvolvimento sustentável, identificou-se ser imprescindível uma interação mútua e a complementaridade entre os atores sociais. No caso do setor elétrico, percebeu-se que todos os atores devem atuar ativamente buscando a partir da incorporação de seus papéis de 
responsabilidade interagir com os demais atores. Nesse contexto de interações, percebe-se que ações desenvolvidas pela CELPE estimulam o alcance do consumo sustentável no setor elétrico na medida em que consegue envolver uma grande quantidade de atores sociais direcionados para o desenvolvimento sustentável.

Assim percebe-se que além dos atores selecionados para estudo (Governo, Empresa e Sociedade), outros atores estão envolvidos com esse novo padrão de consumo, são eles: Mídia, Terceiro Setor, Funcionários, Instituição Financiadora, dentre outros atores sociais, tem papéis específicos e imprescindíveis nessa nova prática coletiva. Para questões desse estudo, na medida em que se selecionou o estudo de caso, destacasse o papel responsável da CELPE na busca pela eficiência energética no consumo da energia, o que contribui muito positivamente. Percebe-se ainda que ao longo da pesquisa, torna-se visível a possibilidade de um consumo sustentável no referido setor, bem como efetiva atuação dos diferentes atores sociais.

Assim sendo, identifica-se a relevância e originalidade da presente pesquisa já que se consegue atender ao objetivo proposto e contribuir para a discussão sobre a temática. Vale salientar que não se objetivou esgotar as discussões sobre a temática. Toma-se como limitação da pesquisa, a análise de apenas um projeto na empresa selecionada, mas entende-se que aquele analisado apresenta contribuições positivas para as discussões. Para novos trabalhos, recomenda-se a ampliação da análise dos projetos, caso seja considerada a empresa o foco do estudo, ou ainda, a realização da pesquisa sobre consumo sustentável em diferentes setores da economia.

\section{REFERENCIAS}

ASSADOURIAN, E. Ascensão e queda das culturas de consumo. In: WORLDWATCH NSTITUTE. Estado do Mundo, 2010: estado do consumo e o consumo sustentável. Salvador: Uma Ed., 2010

BARDIN, L. Análise de Conteúdo. 4ª ed. Lisboa: Edições 70, 2009.

BAUMAN, Z. Vida para o consumo: a transformação de pessoas em mercadorias. Rio de Janeiro: Jorge Zahar Ed., 2008.

BEDANTE, G. N; SLONGO, L. A. O comportamento do consumo sustentável e suas relações com a consciência ambiental e a intenção de compra de produtos ecologicamente embalados. In Anais... I ENCONTRO DE MARKETING DA ANPAD. Porto Alegre: 2004.

BRASIL. Lei $n^{o}$ 9.991/2000. Planalto Central: 2000. Disponível em: <http://www.planalto.gov.br/ccivil_03/Leis/L9991.htm> Acesso em: dez. 2010. Link

BUARQUE, S. C. Construindo o desenvolvimento local sustentável: metodologia de planejamento. São Paulo: Garamond, 2008. 
CASAGRANDE JR, E. F. Inovação Tecnológica e Sustentabilidade: integrando as partes para proteger o todo. Palestra do Seminário de Tecnologia PPGTE/CEFET-PR: Curitiba, 2003.

CELPE (Companhia Elétrica de Pernambuco). A História. [Online] 2010 a. Disponível em: <http://www.celpe.com.br/> Acesso em: 15 dez. 2010. Link

A CELPE: Pernambuco tem a energia da Celpe. [Online] 2010 b. Disponível em: <http://www.celpe.com.br/> Acesso em: dez. 2010. Link

2010c.
Celpe firma convênio com o Instituo Walmart e o Estaleiro Atlântico Sul. [Online]
Disponível <http://www.celpe.com.br/SALA\%20DE\%20IMPRENSA/RELEASES/release.asp?c=137\&c od=222> Acesso em: dez. 2010. $\underline{\text { Link }}$

CORRÊA, A. P. M.; SILVA, M. E.; MELO, E. S. A logística reversa como componente facilitador da inter-relação entre empresas, governo, e sociedade em busca do desenvolvimento sustentável. In Anais... XII ENCONTRO INTERNACIONAL DE GESTÃO EMPRESARIAL E MEIO AMBIENTE. São Paulo: FGV-EAESP, 2010.

CORTEZ, A. T. C.; ORTIGOZA, S. A. G. Consumo Sustentável: conflitos entre necessidades e desperdício. São Paulo: Editora UNESP, 2007.

COSTA, F. J.; OLIVEIRA, L. G. L. Produção e consumo sustentável: Um estudo de caso. In: Anais... XII Simpósio de Administração da Produção, Logística e Operações Internacionais SIMPOI. São Paulo: 2009.

DIÁRIO DE PERNAMBUCO. Prefeitura e Celpe vão trocar geladeiras de beneficiados pelo Prometropole. [Online] 2010. Disponível em: $<\mathrm{http}$ ///www.diariodepernambuco.com.br/economia/nota.asp?materia=20100527074654\&ass unto $=69$ \&onde $=$ Economia $>$ Acesso em: dez. 2010. Link

ELKINGTON, J. Canibais com garfo e faca. São Paulo: Makroon Books, 2001.

FERNANDINO, J. A.; OLIVEIRA, Janete L. Arquiteturas organizacionais para a área de $P \& D$ em empresas do setor elétrico brasileiro. Revista Administração Contemporânea [online]. 2010, vol.14, n.6, pp. 1073-1093.

FOLHA PE. Mais 800 unidades de geladeiras serão distribuídas na RMR e Sertão. [Online] 2010. Disponível em: <http://www.folhape.com.br/index.php/noticias-geral/33destaquenoticias/608174-800-unidades-na-rmr-e-sertao> Acesso em: dez. 2010. Link

GIACOMINI FILHO, G. Meio Ambiente \& Consumismo. São Paulo: Editora Senac São Paulo, 2008. 
GIL, A. C. Como Elaborar Projetos de Pesquisa. 3. ed. São Paulo: Atlas, 1991.

GOLDENBERG, J.; PRADO, L. T. S. Reforma e crise do setor elétrico no período FHC. Tempo social [online]. 2003, vol.15, n.2, pp. 219-235.

GOLDENBERG, M. A arte de pesquisar: como fazer pesquisa qualitativa em ciências sociais. Rio de Janeiro: Record, 2009.

GOMES, Daniela V. Educação para o Consumo Ético e Sustentável. Revista eletrônica Mestrado em Educação Ambiental. v. 16, jun 2006.

GONÇALVES-DIAS, S. L. F.; MOURA, C. Consumo Sustentável: muito além do consumo "verde". In: Anais... XXXI ENCONTRO DA ANPAD. Rio de Janeiro: 2007.

GRUPO NEOENERGIA. Histórico do setor elétrico. 2008. Disponível em: <http://www.neoenergia.com/section/historico-setor-eletrico.asp> Acesso em: dez. 2010. Link

INSTITUTO AKATU. Akatu pelo consumo consciente. 2001. Disponível em: $<$ http://www.akatu.org.br/>. Acesso em: nov. 2010. Link

JACKSON, T. Sustainable Consumption. In: ATKINSON, G.; DIETZ, S.; NEUMAYER, E. (editors). Handbook of Sustainable Development. Edward Elgar Publishing, 2007.

MALHOTRA, N. Pesquisa de Marketing: uma orientação aplicada. 4. ed. Porto Alegre: Bookman, 2006.

McCRACKEN, G. Cultura e consumo: novas abordagens ao caráter simbólico dos bens e das atividades de consumo. Rio de Janeiro: MAUAD, 2003.

MICHAELIS, L. The role of business in sustainable consumption. Journal of Cleaner Production, v.11. 2003.

OLIVEIRA, M. M. Como fazer pesquisa qualitativa. Recife: Ed. Bagaço, 2005.

OLIVEIRA, V. M.; CÂNDIDO, G. A. Contemporaneidade do Consumo Sustentável e as suas correlações com as Práticas Empresariais e o Comportamento do Consumidor. In: Anais... V ENCONTRO NACIONAL DA ANPPAS. Florianópolis, 2010.

ORTIGOZA, S. A. G. Consumo sustentável: um compromisso de todos. Território \& Cidadania, v. 2, n. 2. 2002.

PIRES, J. C. L. Desafios da reestruturação do setor elétrico. Textos para discussão 76. BNDES, $2000 . \quad$ Disponível em: <http://www.bndes.gov.br/SiteBNDES/export/sites/default/bndes_pt/Galerias/Arquivos/conhe cimento/td/Td-76.pdf> Acesso em: 16 dez. 2010. Link 
PNUMA (Programa das Nações Unidas para o Meio Ambiente). Rumo ao consumo sustentável na América latina e caribe. Workshop sobre consumo sustentável na América latina e caribe. São Paulo: 2001.

PORTILHO, M. F. F. Sustentabilidade Ambiental, consumo e cidadania. São Paulo: Cortez, 2005.

RAY, M. Qual o novo paradigma nos negócios? In: RAY, Michael; RINZLER, Alan (orgs). O novo paradigma nos negócios: Estratégias emergentes para liderança e mudança organizacional. São Paulo: Editora Cultrix, 1999.

RICHARDSON, R. J. et al. Pesquisa Social: métodos e técnicas. 3. ed. São Paulo: Atlas, 2008.

SACHS, I. Rumo à ecossocioeconomia: Teoria e prática do desenvolvimento. São Paulo: Cortez, 2007.

SANTOS, T. C.; et al. Movimento do Consumo Consciente: do Cidadão Consumidor ao Consumidor Cidadão? In: Anais... ENCONTRO DE ADMINISTRAÇÃO PÚBLICA E GOVERNANÇA - EnAPG. Salvador, 2008.

SCHUMACHER, E. F. Lo pequeno es hermoso. 3. Ed. Espana: Tursen S.A, 2001.

SILVA, M. E. Consumo Sustentável: Em busca de um constructo. In Anais... XII ENCONTRO INTERNACIONAL DE GESTÃO EMPRESARIAL E MEIO AMBIENTE. São Paulo: FGV-EAESP, 2010.

SILVA, M. E.; CORRÊA, A. P. M. Como a temática do consumo sustentável vem sendo abordado nas Instituições de Ensino Superior do Recife? In Anais... XII ENCONTRO INTERNACIONAL DE GESTÃO EMPRESARIAL E MEIO AMBIENTE. São Paulo: FGVEAESP, 2010.

SLATER, D. Cultura do consumo \& modernidade. São Paulo: Nobel, 2002.

SOUSA, W. L. Impacto ambiental de hidrelétricas: Uma análise de duas abordagens. $154 \mathrm{f}$. Dissertação (Mestrado em Ciências em Planejamento Energético). Programa de Pósgraduação em Engenharia. Universidade Federal do Rio de Janeiro. Rio de Janeiro: 2000.

TAYLOR, B. Encouraging industry to assess and implement clear production measures. Journal of cleaner production, v. 14. 2006.

TUKKER, A.; et al. Fostering change of sustainable consumption and production: an evidence based view. Journal of cleaner production, v. 16. 2008. 
WCED - World Comission on Environment and Development. Report Our commom future. Genebra, 1987. Disponível em: <http://www.un-documents.net/wced-ocf.htm.>. Acesso em: jul. 2010. Link

WWF-BRASIL. Cenários para um Setor Elétrico Eficiente, Seguro e Competitivo. Estudos avançados [online]. 2007, vol.21, n.59, p. 59-66.

YIN, R. K. Applications of case study research. Califórnia: SAGE Publications, 1993. 